\title{
An examination of the effectiveness of traps and baits as a possible means of harvesting crayfish, Cherax quadricarinatus in Sanyati Basin, Lake Kariba, Zimbabwe
}

\author{
L Mhlanga', L Marufu', G Mupandawana² and T Nhiwatiwa',2 \\ 'Department of Biological Sciences, University of Zimbabwe, PO Box MP 167, Mt. Pleasant, Harare, Zimbabwe \\ ${ }^{2}$ Lake Kariba Research Station, University of Zimbabwe, Private Bag 48, Kariba, Zimbabwe
}

Although Cherax quadricarinatus is now established in Lake Kariba, there is a lack of information on the appropriate gear technology and bait for its exploitation for either management or commercial purposes. The effectiveness of three trap designs and three bait types was investigated in order to identify the best means for harvesting C. quadricarinatus in Lake Kariba. The cylindrical and rectangular traps had higher and similar CPUE, which were significantly higher than those of the Opera house trap at all sites. Trap type did not influence sex ratio. Liver, sadza and fish heads were all similarly effective as bait. Either sadza-baited cylindrical or rectangular traps can be effectively employed to either harvest crayfish in order to maintain a low population, thereby mitigating potential adverse impacts, or for commercial purposes. This should be corroborated with monitoring and further research.

\section{INTRODUCTION}

The introduction of non-native crayfishes into aquatic ecosytems has become a problem in southern Africa (Nunes et al., 2016; 2017), and also globally (Twardochleb et al., 2013; Souty-Grosset et al., 2016). These species are now considered to be a major threat to freshwater biodiversity and ecosystem functioning (Lodge et al., 2000; 2012). They can act as novel predators, competitors, and vectors of pathogens and diseases, while hybridising with native crayfishes thus reducing their populations (Lodge et al., 2012). They also consume fish eggs as well as large quantities of macrophytes, so bringing about indirect and direct effects on other invertebrates (Carpenter, 2005). Consequently, freshwater crayfish have been described as keystone species which can alter multiple trophic levels of invaded ecosystems (Dorn and Wojdak, 2004).

The Australian redclaw crayfish, C. quadricarinatus (Von Martens, 1868) was first reported on the Zambian side of Lake Kariba in 1992 (Thys Van den Audenaerde, 1994) and had become established by 2008 and 2009 on the Zambian and Zimbabwean sides, respectively (Nakayama et al., 2010; Marufu et al., 2014). Although its introduction into southern Africa has been discouraged as it is highly invasive and likely to pose adverse ecological impacts, it is becoming increasingly widespread in the region (De Moor, 2002; Nunes et al., 2016; 2017).

The objective of this study was to assess the effectiveness of three cage designs and three potential baits types in order to determine the best means for harvesting of C. quadricarinatus in Lake Kariba. Appropriate gear needs to be recommended in order to effectively intentionally exploit crayfish, which can control the population thereby potentially minimizing the ecological impacts (Lodge et al., 2012; Conde and Dominguez, 2015), or for commercial purposes. An opportunity exists in Lake Kariba to consider intentional exploitation as a strategy to minimise potential ecological impacts of an invasive species or enable commercial benefit; however, information on catch and effort relationship and the appropriate gear technology for exploitation is not available.

\section{MATERIALS AND METHODS}

The study was carried out in Lake Kariba, a tropical man-made lake that is located in the north-west of Zimbabwe and is shared between Zambia and Zimbabwe. The study was conducted at 3 sites in the lake's eastern (Sanyati) basin, namely Kasese, Platform, and Antelope, from January to December 2016 (Fig. 1). Kasese has a gentle sloping shore and coarse substratum. Platform is very flat with a muddy substratum while Antelope has steep slopes with a substratum that comprises of pebbles. The dominant aquatic macrophytes at all the sites were Vallisneria aethiopica, Lagarosiphon ilicifolius and Eichhornia crassipes.

Sampling was carried out over 1 night, monthly at the 3 sites using 3 trap designs, namely: the rectangular trap, cylindrical trap and opera house trap (Table 1). Six cages of each design were set at each site, left overnight and taken out the following morning. Cooked maize meal paste (sadza) was used as bait in the traps. Traps were thrown into water of $<5 \mathrm{~m}$ deep. Crayfish from each cage were taken to the laboratory where they were weighed and their carapace lengths measured. Statistical analysis was done using the computer software Stastica Version 7 (StatSoft 2004). Significant differences among the traps were tested for using the Kruskal-Wallis ANOVA, as the data did not meet the requirements for parametric tests. Where there were significant differences among the traps $(p<0.05)$, Mann-Whitney pairwise comparisons were used to test for differences between traps.

\section{CORRESPONDENCE}

L Mhlanga

EMAIL

Imhlanga67@gmail.com

\section{DATES}

Received: 23 April 2019

Accepted: 14 August 2020

\section{KEYWORDS}

bait

cylindrical trap opera house trap rectangular trap trap type

\section{COPYRIGHT}

(c) The Author(s) Published under a Creative Commons Attribution 4.0 International Licence (CC BY 4.0) 


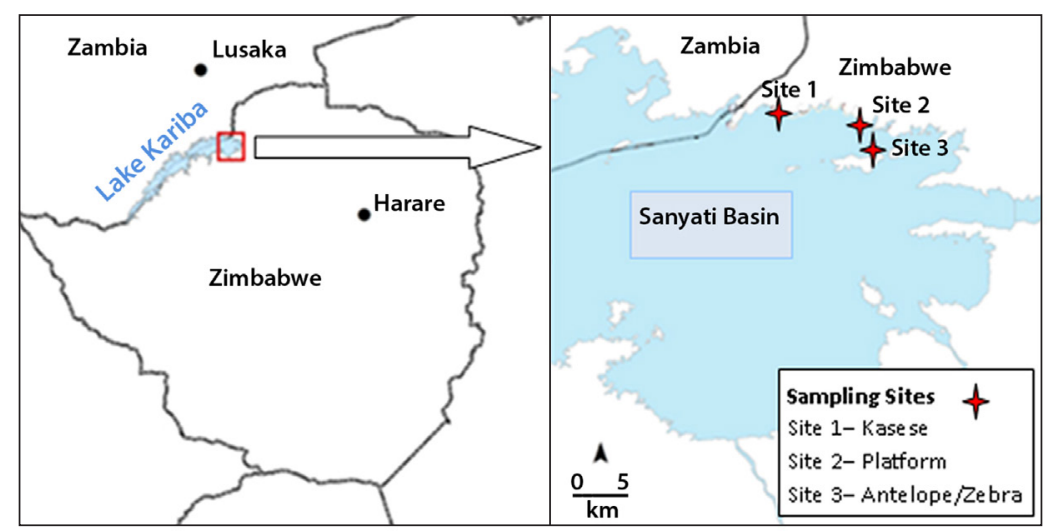

Figure 1. Location of the Sanyati Basin, Lake Kariba and the location of the sampling sites

Table 1. The dimensions of the three trap designs

\begin{tabular}{lccc}
\hline Dimension & Rectangular trap & Cylindrical trap & Opera house trap \\
\hline Width $(\mathrm{mm})$ & 400 & 400 & 400 \\
Length $(\mathrm{mm})$ & 400 & 1000 & 700 \\
Height $(\mathrm{mm})$ & 1000 & - & 300 \\
Trap entrance $(\mathrm{mm})$ & 100 & 100 & 100 \\
\hline
\end{tabular}

Table 2. The mean catch per unit effort (CPUE) expressed as the number and weight of crayfish caught per trap per night at the three sampling sites, January to December 2016

\begin{tabular}{|c|c|c|c|}
\hline Site & Design & Mean number \pm SD & Mean weight $\pm \mathrm{SD}(\mathrm{kg})$ \\
\hline \multirow[t]{3}{*}{ Antelope } & Opera house trap & $1.08 \pm 1.06$ & $0.022 \pm 0.022$ \\
\hline & Rectangular trap & $3.25 \pm 2.62$ & $0.070 \pm 0.049$ \\
\hline & Cylindrical trap & $2.46 \pm 1.82$ & $0.067 \pm 0.049$ \\
\hline \multirow[t]{3}{*}{ Platform } & Opera house trap & $0.46 \pm 0.51$ & $0.006 \pm 0.008$ \\
\hline & Rectangular trap & $3.38 \pm 2.35$ & $0.078 \pm 0.052$ \\
\hline & Cylindrical trap & $2.27 \pm 1.57$ & $0.048 \pm 0.033$ \\
\hline \multirow[t]{3}{*}{ Kasese } & Opera house trap & $0.46 \pm 0.41$ & $0.015 \pm 0.017$ \\
\hline & Rectangular trap & $4.33 \pm 3.295$ & $0.176 \pm 0.145$ \\
\hline & Cylindrical trap & $2.04 \pm 1.36$ & $0.080 \pm 0.057$ \\
\hline
\end{tabular}

Table 3. The sex ratio (number of females per male) of C. quadricarinatus from different trap types, January to December 2016

\begin{tabular}{lccccccccccccc}
\hline Trap type & Jan & Feb & Mar & Apr & May & Jun & Jul & Aug & Sep & Oct & Nov & Dec & Mean \\
\hline Rectangular & 2.28 & 0.67 & 4.99 & 1.18 & 0.92 & 0.81 & 1.25 & 0.75 & 0.94 & 1.36 & 0.64 & 1.50 & $1.44 \pm 1.21$ \\
Opera house & 1.00 & 2.00 & 1.00 & 1.00 & 3.00 & 2.00 & 0.40 & 1.00 & 1.60 & 0.88 & 0.43 & 1.60 & $1.33 \pm 0.75$ \\
Cylindrical & 1.25 & 0.86 & 1.67 & 0.50 & 0.67 & 0.78 & 1.62 & 0.59 & 0.69 & 1.13 & 0.96 & 0.80 & $0.96 \pm 0.38$ \\
\hline
\end{tabular}

The effectiveness of baits was tested using chicken liver; sadza (cooked maize meal); fish heads and a control (without bait). Opera house traps (Marufu et al., 2014; Table 1) were used in the assessment of bait effectiveness. The experiment was carried out at Kasese Bay (Fig. 1). Three cages (replicates) were used for each treatment and the experiment was run once a month for 10 months, with no sampling taking place in March and April 2016. Traps were set overnight and removed in the morning. MannWhitney U-Test was used to test the differences in the effectiveness of the different trap types using catch per unit effort data.

\section{RESULTS AND DISCUSSION}

In this study we tested 3 potential gear types that can be used in Lake Kariba waters. Both the rectangular and cylindrical traps can be effective traps to harvest C. quadricarinatus in Lake Kariba. The most effective trap was the rectangular trap which caught a total of $24.24 \mathrm{~kg}$ in the entire sampling campaign (mean $2.08 \mathrm{~kg}$ per month), followed by the circular $(14.08 \mathrm{~kg}$; mean $1.17 \mathrm{~kg}$ per month) and opera house (3.09 kg; mean $0.26 \mathrm{~kg}$ per month) traps. The rectangular trap seemed to be the most effective, with the highest mean CPUE, while the opera house trap was the least efficient with the lowest CPUE at all three sampling sites (Table 2). This pattern was generally consistent over time, although there were some occasions when the CPUE in the opera house and cylindrical traps exceeded that of the rectangular traps (Fig. 2). There was no clear seasonal pattern in the CPUE, although catches were generally higher in the last 6 months of the investigation (Fig. 2). A comparison of the three traps using monthly data across the three sites showed significant differences in crayfish CPUE (K-W ANOVA $H=46.86 ; p<0.0001$ ), weight (K-W ANOVA $H=52.36 ; p<0.0001$ ) and number (K-W ANOVA $H=46.86$; $p<0.0001)$. The sex ratios varied from month to month and trap to trap, but the average did not differ from a 1:1 ratio (Table 3). The monthly differences are probably due to chance. The length frequency distribution showed sexual dimorphism (Fig. 3), where the modal lengths of females and males were $50 \mathrm{~mm}$ and $60 \mathrm{~mm}$, respectively. Marufu et al.(2014) also reported smaller females $(60 \mathrm{~mm})$ than males $(80 \mathrm{~mm})$, an observation attributed to the slower growth rates of female relative to males (Lawrence, 2004). Most crayfish caught were above a sexually mature range of 0.045-0.050 kg (Ruscoe, 2006), as observed by Marufu et al. (2014). 


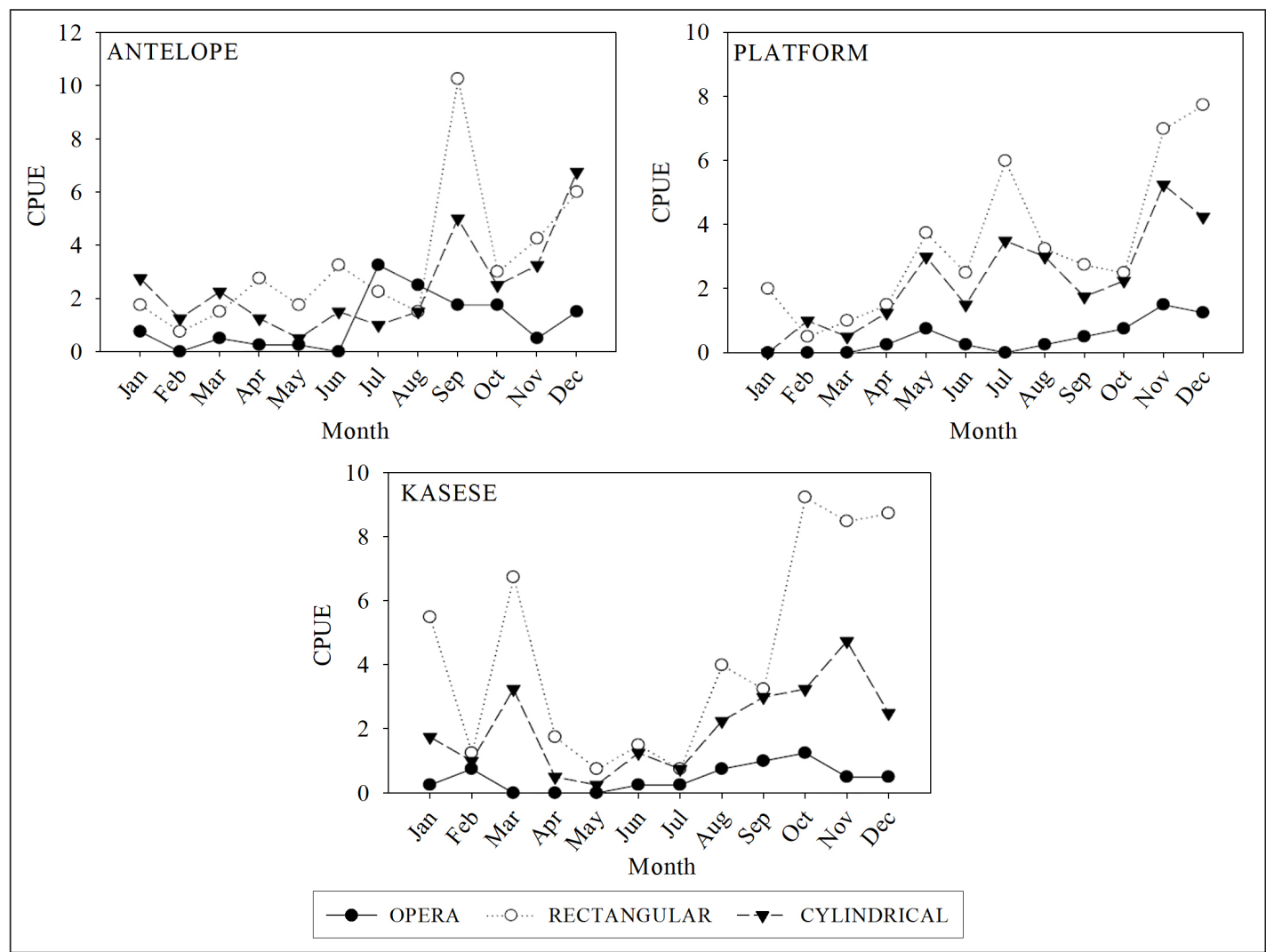

Figure 2. Variation in the CPUE (number caught per trap per night) of C. quadricarinatus at the three sampling stations, January to December 2016

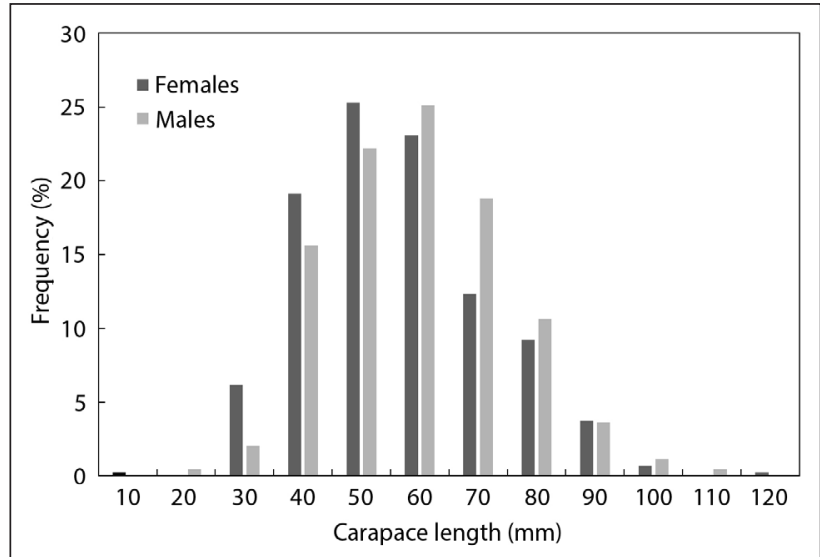

Figure 3. Length-frequency distribution of 455 female and 442 male C. quadricarinatus trapped in the Sanyati Basin, Lake Kariba, from JanuaryDecember 2016

Table 4. Effect of different bait types on C. quadricarinatus catches and numbers during three trials in the Sanyati Basin, Lake Kariba

\begin{tabular}{|c|c|c|c|c|c|c|}
\hline \multirow[t]{2}{*}{ Bait type } & \multicolumn{2}{|c|}{ Trial 1} & \multicolumn{2}{|c|}{ Trial 2} & \multicolumn{2}{|c|}{ Trial 3} \\
\hline & Weight (kg) & Number & Weight (kg) & Number & Weight (kg) & Number \\
\hline Liver & $0.294 \pm 0.359$ & $5.7 \pm 6.32$ & $0.253 \pm 0.148$ & $3.6 \pm 1.82$ & $0.175 \pm 0.113$ & $5 \pm 4.24$ \\
\hline Sadza & $0.301 \pm 0.253$ & $5.3 \pm 4.46$ & $0.063 \pm 0.091$ & $2.6 \pm 3.04$ & $0.379 \pm 0.216$ & $10 \pm 7.07$ \\
\hline Fish heads & $0.369 \pm 0.359$ & $6.3 \pm 5.00$ & $0.217 \pm 0.197$ & $3.8 \pm 2.17$ & $0.281 \pm 0.051$ & $6 \pm 1.41$ \\
\hline Control & $0.052 \pm 0.053$ & $1.4 \pm 1.40$ & $0.094 \pm 0.144$ & $1.4 \pm 1.34$ & $0.010 \pm 0.025$ & $2.5 \pm 0.71$ \\
\hline
\end{tabular}

The CPUE for all traps fell within the range observed by Marufu et al. (2014), who reported a maximum of 4 individuals trap $^{-1} \cdot$ night $^{-1}$, with the average CPUE ranging from 1.1-4.0 individuals.trap ${ }^{-1}$ -night ${ }^{-1}$. The CPUE observed during this study ranged from a minimum of 0.46 to a maximum of 4.3 individuals trap $^{-1} \cdot$ night $^{-1}$.

Comparison of the different baits showed that there were overall significant differences in effectiveness amongst the baits (KruskalWallis ANOVA $H=8.843 ; p=0.031$.) The unbaited control traps constistently trapped lower catches compared to the baited traps
(Table 4). Fishers will require cheap local resources to use as bait in these traps. On testing the effectiveness of different baits to capture crayfish, results showed that chicken liver, sadza and fish heads were effective as bait. Since sadza is a cheap local resource, it can be effectively used as bait by subsistence fishers.

Cherax quadricarinatus is an alien conflict-generation species (Nunes et al., 2012), that has established populations within the Zambezi River systems including Lake Kariba. It is a species that is likely to cause negative impacts to the ecosystem but 
also has potential to provide socio-economic benefits (Zengeya et al., 2017). Populations have established in streams and large reservoirs in the lower Zambezi and the species is spreading to the upper Zambezi Basin (Nunes et al., 2016). Southern African waters seem to provide a niche for it as wild populations have established in Zambia, Zimbabwe, Mozambique, Swaziland and South Africa (Nunes et al., 2017). Its spread shows that there is an urgent need to institute adaptive strategies to control it, although unrestricted harvesting for human consumption may create the temptation to introduce the species to uninvaded regions as an economic resource (Nunes et al., 2012).

In conclusion, sadza-baited rectangular or cylindrical traps can be effectively used to harvest C. quadricarinatus in Lake Kariba which can reduce the population size. This can be done while researchers are still undertaking detailed studies on its current status, distribution and potential impact in Lake Kariba waters.

\section{ACKNOWLEDGEMENTS}

This study was funded by the University of Zimbabwe Research Board. Logistical support was provided by the University Lake Kariba Research Station and the Department of Biological Sciences, University of Zimbabwe.

\section{REFERENCES}

CARPENTER J (2005) Competition for food between an introduced crayfish and two fishes endemic to the Colorado River Basin. Environ. Biol. Fishes 72 335-342. https://doi.org/10.1007/s10641-004-2588-z

CONDE A and DOMINGUEZ J (2015) A proposal for the feasible exploitation of the Red swamp crayfish, Procambrus clarkii in introduced regions. Conserv. Lett. 8 (6) 440-448. https://doi.org/ $10.1111 /$ conl.12164

DE MOOR IJ (2002) Potential impacts of alien freshwater crayfish in South Africa. Afr. J. Aquat. Sci. 27 125-139. https://doi.org/10.2989/ 16085914.2002 .9626584

DON NJ and WOJDAK JM (2004) The role of omnivorous crayfish in littoral communities. Oecologia 14 150-159. https://doi.org/10.1007/ s00442-004-1548-9

LAWRENCE CC (2004) All-male hybrid (Cherax albidus X Cherax rotundus) yabbies' grow faster than mixed-sex (C. albidus $\mathrm{X}$ C. albidus) yabbies. Aquaculture 236 211-220. https://doi.org/10. 1016/j.aquaculture.2003.10.019

LODGE D, TAYLOR C, HOLDICH DM and SKURDAL J (2000) Non indigenous crayfishes threaten North American freshwater biodiversity: lessons from Europe. Fisheries 25 (8) 7-20. https://doi. org/10.1577/1548-8446(2000)025<0007:NCTNAF >2.0.CO;2
LODGE DM, DEINES A, GHERARDI F, YEO DCJ, ARCELLA T, ELGIN AK and YIWEN Z (2012) Global introductions of crayfishes: evaluating impact of species invasions on ecosystem services. Annu. Rev. Ecol. Evol. Syst. 43 (1) 449-472. https://doi.org/10.1146/ annurev-ecolsys-111511-103919

MARUFU LT, PHIRI C and NHIWATIWA T (2014) Invasive Australian Redclaw crayfish, Cherax quadricarinatus in the Sanyati Basin of Lake Kariba: a preliminary investigation. Afr. J. Aquat. Sci. 39 (2) 233-236. https://doi.org/10.2989/16085914.2014.922457

NAKAYAMA SMM, IKENAKA Y, MUZANDU K, CHOONGO K, OROSZLANY B, TERAOKA H, MIZUNO $\mathrm{N}$ and ISHIZUKA $\mathrm{M}$ (2010) Heavy metal accumulation in lake sediments, fish (Oreochromis niloticus and Serranochromis thumbergi) and crayfish (Cherax quadricarinatus) in Lake Itezhi-tezhi and Lake Kariba, Zambia. Arch. Environ. Contam. Toxicol. 59 291-300. https://doi. org/10.1007/s00244-010-9483-8

NUNES AL, DOUTHWAITE RJ, TYSER B, MEASEY GJ and WEYL OLF (2016) Invasive crayfish threaten Okavango Delta. Front. Ecol. Environ. 14 237-238. https://doi.org/10.1002/fee.1287

NUNES AL, ZENGEYA TA, HOFFMAN AC, MEASEY GJ and WEYL OLF (2017) Distribution and establishment of the alien Australian redclaw crayfish Cherax quadricarinatus in South Africa and Swaziland. PeerJ. 5 e3135. https://doi.org/10.7717/peerj.3135

NUNES MA, KUEBBING S, DIMARCO, RD and SIMBERLOFF D (2012) Invasive species to eat or not to eat, that is the question. Conserv. Lett. 5 334-341. https://doi.org/10.1111/j.1755-263X.2012. 00250.x

RUSCOE I (2006) Redclaw crayfish aquaculture (Cherax quadricarinatus). Fishnote No. 32. Darwin Fisheries, Northern Territory Government.

STATSOFT (2004) STATISTICA (data analysis software system). Version 7.0. www.statsoft.com (Accessed 15 January 2019).

SOUTY-GROSSET C, HOLDICH DM, NOẼL PY, REYNOLDS JD and HAFFNER P (eds.) (2016) Atlas of Crayfish in Europe. Museum National d'Histoire Naturelle, Paris. 187 pp.

THYS VAN DEN AUDENAERDE DFE (1994) Introduction of aquatic species into Zambian waters, and their importance for aquaculture and fisheries. ALCOM Field Document No. 24. FAO/ALCOM Project, Harare. 29 pp.

TWARDOCHLEB LA, OLDEN JD AND LARSON ER (2013) A global meta-analysis of the ecological impacts of non-native crayfish. Freshwater Sci. 32 (4) 1367-1382. https://doi.org/10.1899/12-203.1

ZENGEYA T, IVEY P, WOODFORD DJ, WEYL O, NOVOA A, SHACKLETON R, RICHARDSON D and VAN WILGEN B (2017) Managing conflict-generating invasive species in South Africa: challenges and trade-offs. Bothalia 47 (2) a2160. https://doi. org/10.4102/abc.v47i2.2160 